\title{
Fault Location in the Transmission Network Using a Discrete Wavelet Transform
}

\author{
Majid Dashtdar, Masoud Dashtdar* \\ Electrical Engineering Department, Bushehr Branch, Islamic Azad University, Bushehr, Iran
}

Email address:

Dashtdar.m@gmail.com (Masoud D.)

${ }^{*}$ Corresponding author

\section{To cite this article:}

Majid Dashtdar, Masoud Dashtdar. Fault Location in the Transmission Network Using a Discrete Wavelet Transform. American Journal of Electrical and Computer Engineering. Vol. 3, No. 1, 2019, pp. 30-37. doi: 10.11648/j.ajece.20190301.14

Received: March 19, 2019; Accepted: April 17, 2019; Published: June 25, 2019

\begin{abstract}
In this paper, a discrete wavelet transform (DWT) has been utilized for processing the current signal in order to faultlocation evaluation in network transmission using pre-fault and post-fault current data of both the terminals of a transmission line. In fact, the basis of the work is based on the information recorded before the fault at the end of the line and after the fault at the beginning of the line received by the relay. Obviously, high-frequency components are created at the time of the fault, which is a way of extracting these components using a wavelet transform. In this design, characteristics extorted from synchronous recording of three-phase current signals at the two terminals using DWT. In the following, can accurately estimate the exact location of the fault in the transmission network by extraction and subtracting of the minimum and maximum components of the DWT approximate and detail components of the signal before and after the fault (pre-fault and post-fault).The simulation results reveal that the minimum and maximum extracted components are highly dependent on the fault resistance. Hence, due to increase the fault resistance, the level of signal decomposition has to be increased so that the algorithm is not compromised. Eventually, the proposed method is tested on the transmission network of $735 \mathrm{kV}$ at different distances of the transmission line, which indicates that the proposed algorithm can accurately estimate the fault distance, depending on the type of fault (including low-impedance and high-impedance fault) by changing the signal decomposition level.
\end{abstract}

Keywords: Fault Location, High-Frequency Components, Signal Decomposition, Wavelet Transform

\section{Introduction}

The ultimate goal of a power system is the continuous transfer of energy to consumers. Nowadays, disconnection will cause heavy economic damage to industries and disruptions in the daily lives of subscribers due to the strong dependence of industries and urban consumers on electrical energy. On the other hand, there may be a variety of accidental and unpredictable faults in the power grid. By minimizing the fault detection time, the power loss can be minimized. Various methods have hitherto been proposed for fault detection to accelerate network repair and improve reliability [1]. Moreover, in addition to fault-finding methods, methods are proposed to determine the section or distance of fault, especially in distribution networks [2].

Fault location techniques can be categorized using impedance, travelling waves, high frequency current and fault voltage components, and intelligent learning based methods. Travelling-wave methods have a complex structure and require the accessory equipment [5]. On the other hand, highfrequency component methods will cost a high cost due to the use of high-speed sampling filters [6]. Impedance methods have a relatively simple structure and their use in relay protection is easily possible. Therefore, the most common way of finding a fault is the impedance method. These methods utilize voltage and current frequency phase fuzzy components to locate the fault [7]. Impedance methods are divided into two single-terminal and two-terminal methods. In single-terminal methods, only measured data at the terminals of the relay's installation location is used, which benefits the simplicity of the relationships. The accuracy of these methods is dependent on the fault resistance, homogeneity of the line (impedance constant per unit length of the line), and the determination of the type of fault [8]. The two-terminal method uses measured data at two local and remote terminals. This method will be 
more precise than single-terminal methods due to their dependence on the fault resistance and type of fault. [9-10]

Along with the existing methods, learning algorithm-based methods can also be used as an alternative to locating faults in transmission lines. Learning-based strategies, if executed properly in different conditions and despite the certainty in the system, can show acceptable flexibility and performance. The extraction of efficient features and the application of an appropriate learning algorithm are two main and influential issues in the foundation of learning-based methods. [2-3]

One of the most commonly used functions in signal processing is the wavelet transform, which allows us to extract the high and low frequency components of the signal. It can also play an important role in finding fault locating. For instance, the exact location of the fault can be determined by applying the wavelet transform on high frequency samples of the travelling signal recorded at the beginning of the medium pressure feeders and their end points. It was first shown in [13] that by recording the fault at the two ends of a simple transmission line, regardless of the load along the line, the precise location of the fault can be determined by moving the waves by wavelet transform. In [13] and [4], a method is proposed that uses a wavelet transform to determine the location of a fault using mobile waves in the power system. This method makes it possible to convert a highresolution wavelet to high-frequency components of the fault transmissions. Further, by converting the three-phase voltage signals into the medal components and performing the wavelet transform on the medal signals, a component of regional fashion at high frequencies makes it possible to determine the location of the types of faults [4].

In this paper, the wavelet transform has been used to locate the fault in the transmission line. It should also be noted that
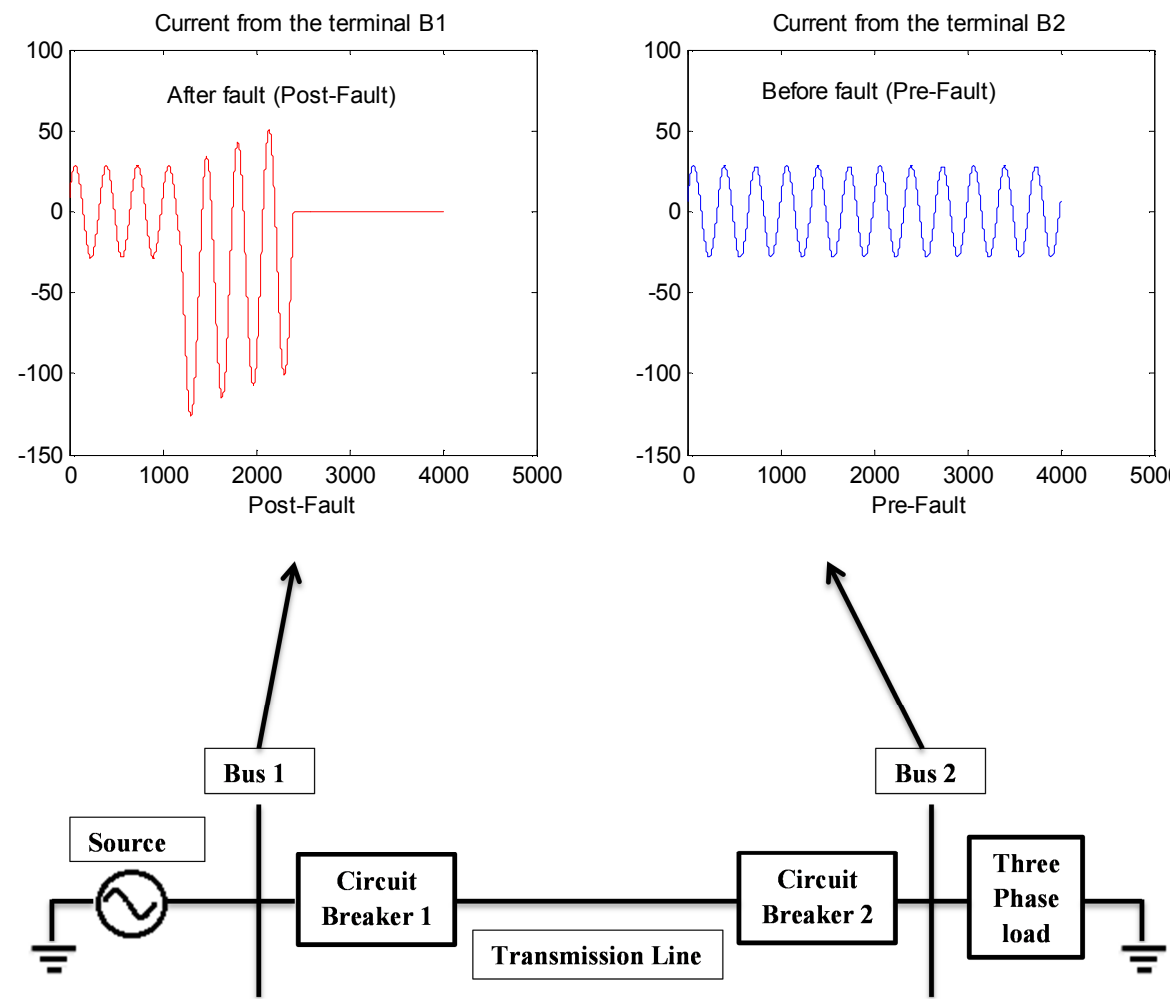

Figure 1. The Pre-Fault and Post-Fault Signal in the Sample Network. in travelling-mode methods, registers are required at a great cost to record the signals sent from the fault location. However, in the proposed method which is only based on current data recorded by the relay, it is easy to estimate the precise location of the fault by transforming the wavelet from it and extracting a series of specific features from the approximate and minor components.

In the second section, the proposed method is described based on the wavelet transform, and in the third section, the network implementation and the results of the fault locator algorithm are presented. Finally, the conclusion is presented in the fourth section.

\section{Proposed Method}

In this paper, the basis of the work is based on the information recorded before the fault at the end of the line and after the fault at the beginning of the line which is received by the relay (as shown in Figure 1). In the following, by transforming the wavelet from the data recorded by the relay, for each signal the current of the four components (including the components of the approximate, horizontal, vertical, diagonal) is obtained. In the next step, must extract the minimum and maximum scales of each component. After this stage, we will have four minimum values and four maximum values for each fault signal. By reducing these scales from the scales before the fault, and obtaining the positive difference and aggregating them together, one can calculate the precise location of the fault. And since these scales depend on the changes in fault resistance, therefore, only a signal decay level is used for low impedance faults and two signal decomposition levels are used for two impedance faults.

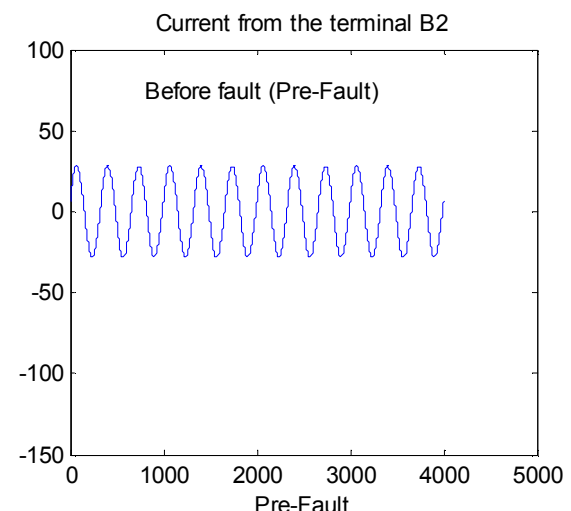




\subsection{Wavelet Transform}

A wavelet transform is capable of displaying a signal by a windowing technique of regions of different sizes. Making it possible to use large time windows when needed to provide accurate information at lower frequencies and smaller windows when it requires high frequency information. One of the major improvements made by wavelet transform is the local analysis of the signal which makes it possible to analyze a small area of a wide signal. In fact, the wavelet is a waveform with a limited time and has an effective zero value. The wavelets are asymmetrical and asymmetric, and their energy is concentrated, limited, and it is around a point. The wavelet transform involves breaking a signal into the transmitted signals and changing the scale of the original wavelet signal (mother wavelet). Therefore, the analysis of signals with sharp changes with the help of wavelets is better than the Fourier analysis with sinusoidal waveforms. Hence, it can be concluded that local variations are better with wavelets.

Wavelet transform has a characteristic that is called Mother Wavelet with several different types. This conversion initially separates the entire wave which is similar to the wavelet of the mother wavelet. Then, the wave separates from the components of the high frequency down to its constituent. Therefore, they can get the initial wave with their sum. For instance, in Figures 2 and 3, the separation of the waves constituting the fault signal seen by the relay is illustrated with one and two levels of decomposition using $\mathrm{db} 4$, respectively. As can be seen, the decomposition of two components is approximate and minor (including horizontal, vertical, diagonal) in each level, which is related to low frequency information and high signal frequency, respectively. Hence, you can use the help of transforming the wavelet of hidden information to the fault.

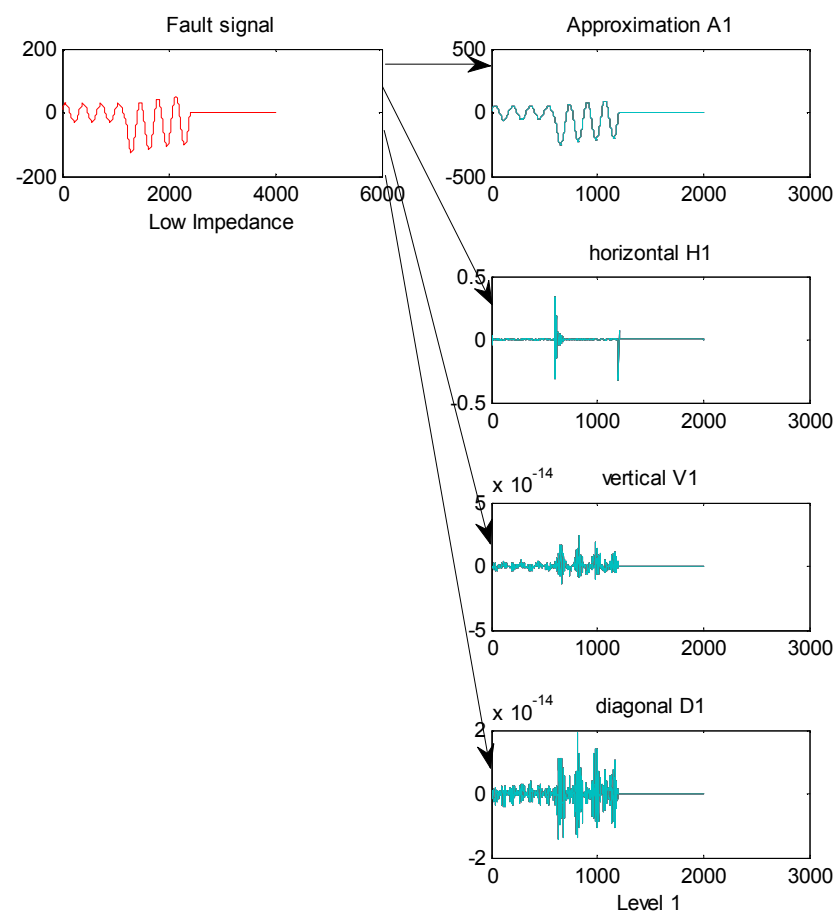

Figure 2. A Fault Level Signal Decomposition for Low Impedance Mode.
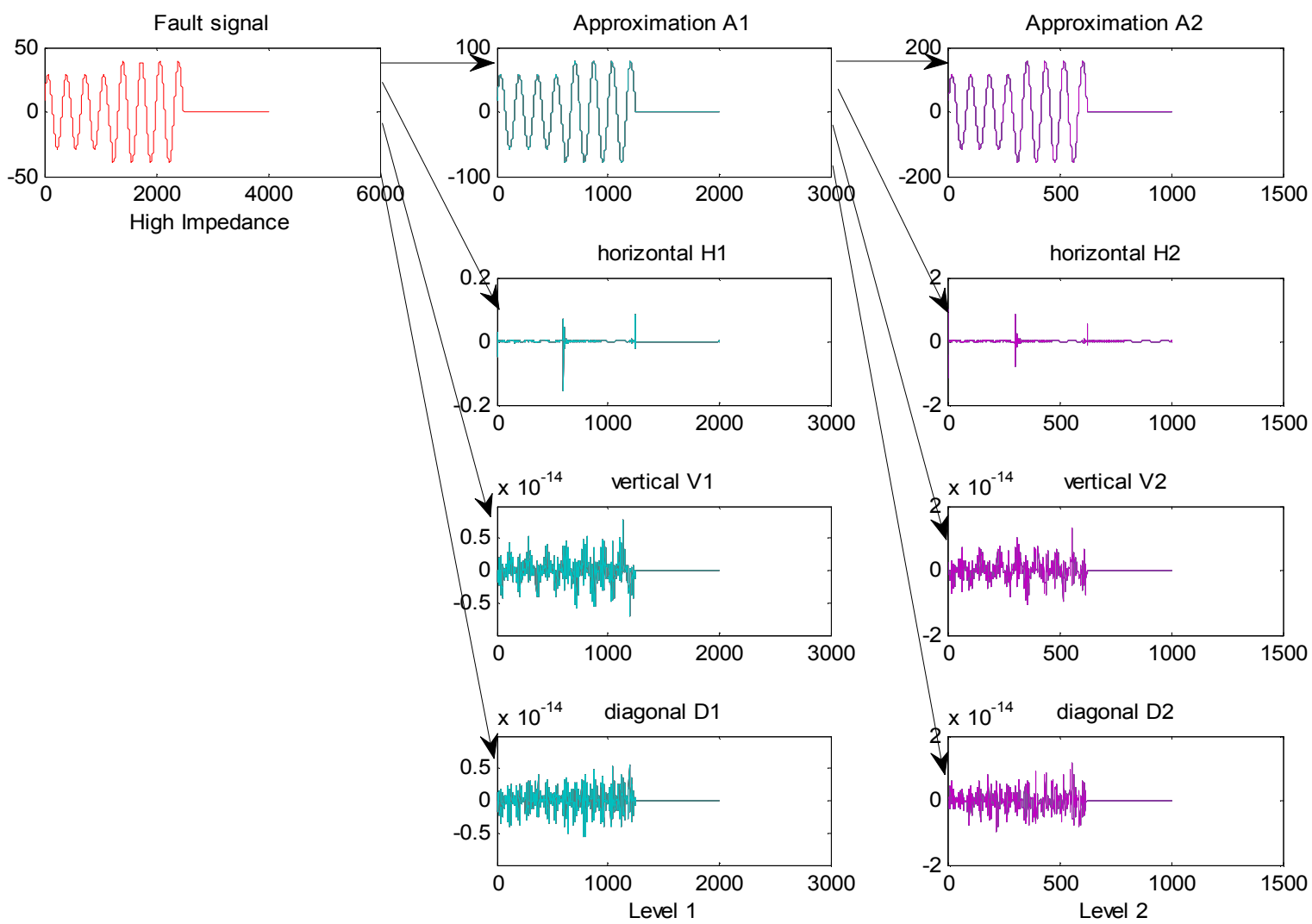

Figure 3. Level-Two Fault Signal Decomposition for High Impedance Mode. 
A wavelet transform is a linear transform that maintains the time allocation in the various frequency components of the given signal. Therefore, can write a function of the scale of $\mathrm{x}$ and a $\psi$ wavelet function as follows:

$$
\operatorname{DWT} \psi \mathrm{f}(\mathrm{m} . \mathrm{k})=\frac{1}{\sqrt{a_{0}^{m}}} \sum_{n} \mathrm{x}(\mathrm{n}) \psi\left[\frac{k-n_{0} b_{0} a^{m}}{a_{0}^{m}}\right]
$$

Where $\psi$ is the maternal wavelet, $a_{0}^{m}$ is the scale parameter, $\mathrm{a}^{\mathrm{m}}$, and $\mathrm{b}_{0}$ and $\mathrm{n}_{0}$ are the transmission parameters. In addition, this paper uses the db4 (daubechies-4) maternal wavelet. And with the help of the following, can implement the wavelet transform process of the current signal in the MATLAB software:

$[\mathrm{A} 1, \mathrm{H} 1, \mathrm{~V} 1, \mathrm{D} 1]=\operatorname{dwt} 2\left(\mathrm{a},{ }^{\prime} \mathrm{db} 4\right) ; \%$ Level-signal decomposition

$[\mathrm{A} 2, \mathrm{H} 2, \mathrm{~V} 2, \mathrm{D} 2]=\operatorname{dwt} 2\left(\mathrm{~A} 1,{ }^{\prime} \mathrm{db} 4\right) ; \quad \%$ Level-Two decomposition

In which

A1, A2 are approximate component of level one and two signal decompositions respectively.

$\mathrm{H} 1, \mathrm{H} 2$ are the horizontal component of the first and second level of signal decomposition, respectively.

$\mathrm{V} 1, \mathrm{~V} 2$ are the vertical component of the surface of one and two signal decompositions, respectively.

D1, D2 are the diagonal component of the level one and

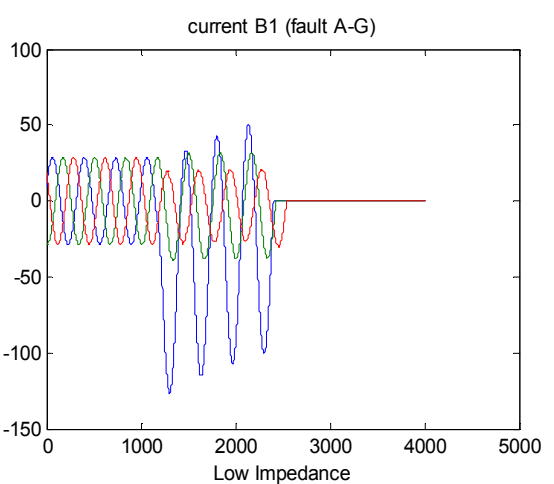

Figure 4. Fault Waveform at Bus 1 and 2 for Low Impedance Mode.

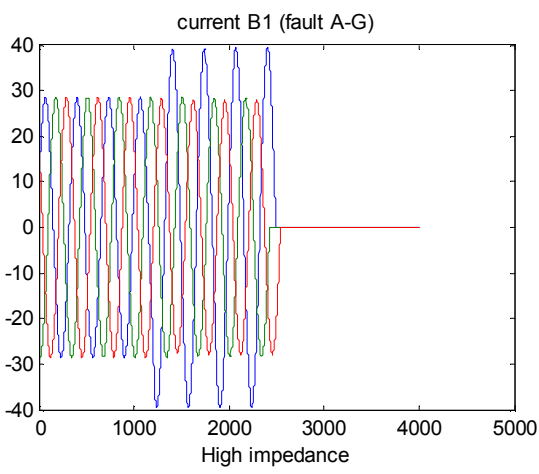

Figure 5. Fault Waveform at Bus 1 and 2 for High Impedance Mode.

As can be seen in Figures 4 and 5, in the impedance fault, the fault current of the phase a, which is seen from the terminals B1 and B2, has increased together. Whereas, in the
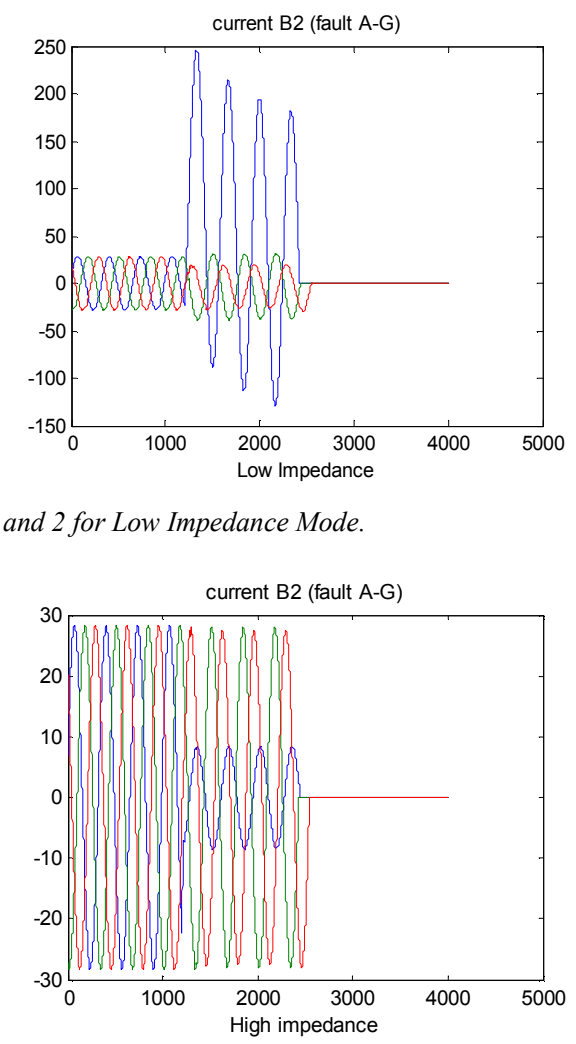

two signal decompositions

a: The signal received from the relay, respectively.

$\mathrm{db} 4$ is the Mother's Wavelet

Therefore, as shown in Figures 2 and 3, can write the fault signal in the form of the sum of the components.

$$
\begin{gathered}
\mathrm{f}(\mathrm{x})=\mathrm{A} 1+(\mathrm{H} 1+\mathrm{V} 1+\mathrm{D} 1)=(\mathrm{A} 2+\mathrm{H} 2+\mathrm{V} 2+\mathrm{D} 2)+(\mathrm{H} 1 \\
+\mathrm{V} 1+\mathrm{D} 1)
\end{gathered}
$$

Furthermore, in this paper, for low impedance faults, a decomposition level is used for high impedance faults from two levels of decomposition. This is due to increased fault resistance, which reduces the level of components. Hence, in order to increase the accuracy of the algorithm, have to increase the signal parsing level.

\subsection{High Impedance Fault Detection}

As mentioned in the previous section, the first step in the proposed fault-detection scheme is the high fault rate which causes the change in the maximum and minimum scales of approximate and minor components. Due to high impedance faults, the voltage waveform changes are small edges. One way to detect the high impedance fault is to see the current waveform recorded in Terminal B2.

high impedance fault, the current at the B1 terminal has increased, however, the current at B2 terminals has decreased due to the high fault resistance. Another way of detecting the 
up and down impedance fault in the network is to calculate

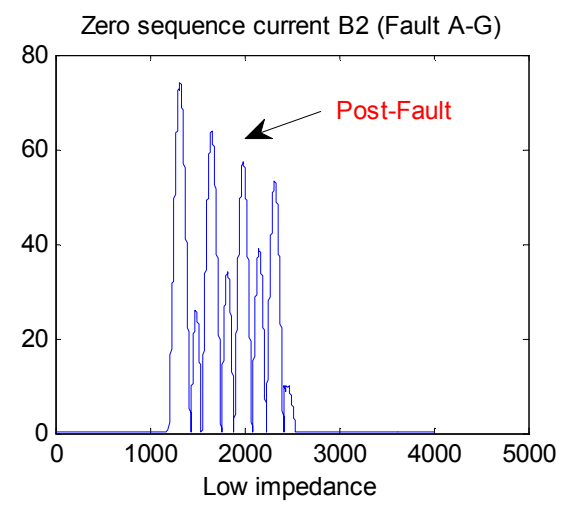

the three-phase zero-sequence current in the B2 terminal

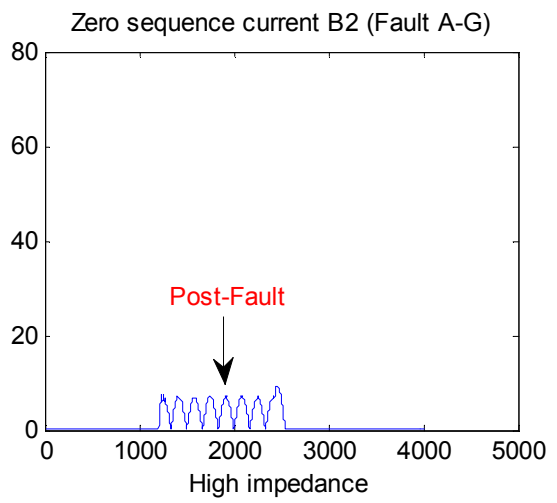

Figure 6. The Current of Zero-Sequence from B2 Terminal in High and Low Impedance Mode.

Comparison of Figure 6 indicates that the zero-sequence current range in the impedance fault mode is lower than the low impedance fault at B2 terminal. After determining the type of fault, it is time to implement the proposed algorithm for fault detection.

\subsection{Extracting the Values of the Maximum and Minimum Scales of the Approximate and Minor Components (Pre-Fault and Post-Fault)}

After determining the level of decomposition, depending on the high and low fault of the impedance, the maximum and minimum scales of each component of the fault signal should be extracted and by subtracting these scales from the scales before the fault and obtaining the positive difference and collecting them, the exact location of the fault should be calculated.
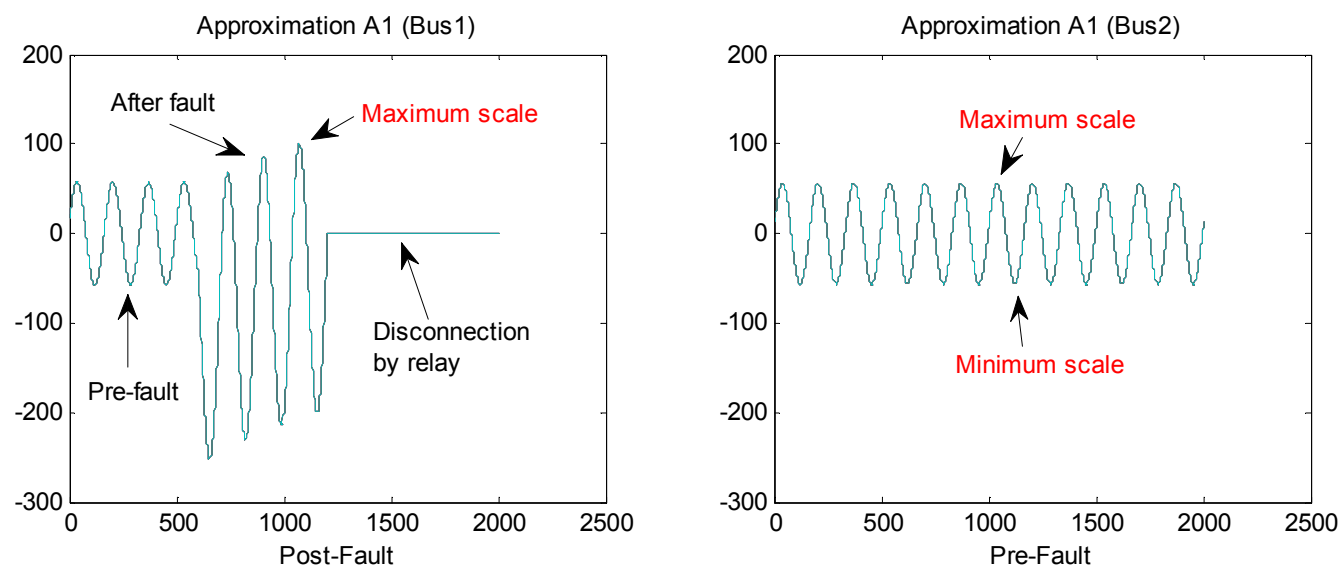

Figure 7. The Approximate Component of the Current Signal on the B2 (Pre-Fault) and on the B1 (Post-Fault).
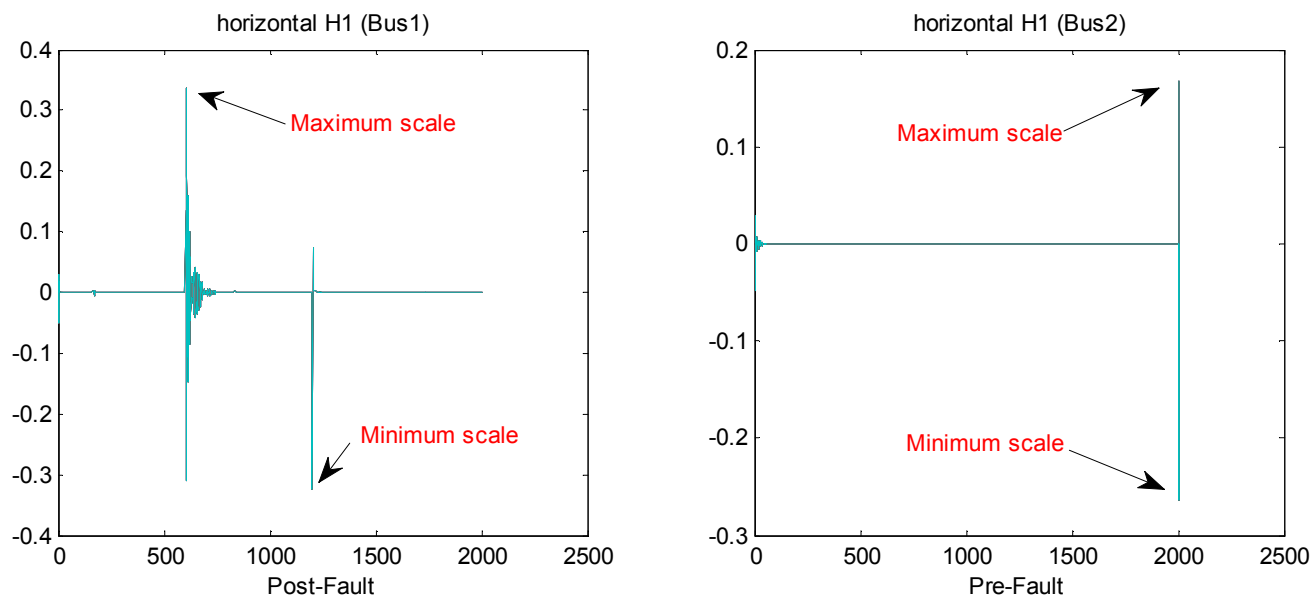

Figure 8. Horizontal Component of the Current Signal on the B2 (Pre-Fault) and on the B1 (Post-Fault). 

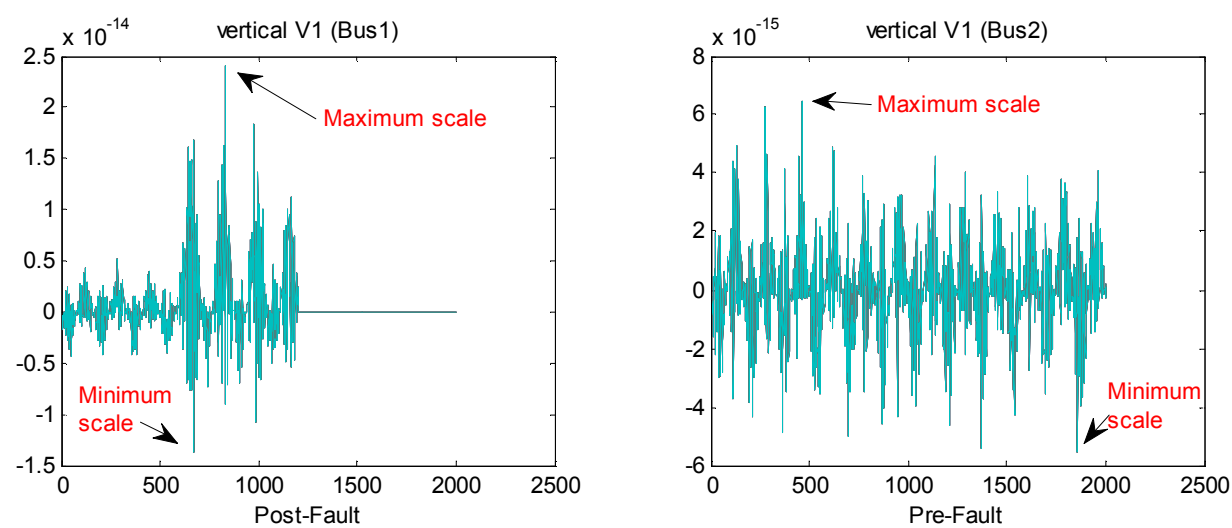

Figure 9. Vertical Component of the Current Signal on the B2 (Pre-Fault) and on the B1 (Post-Fault).
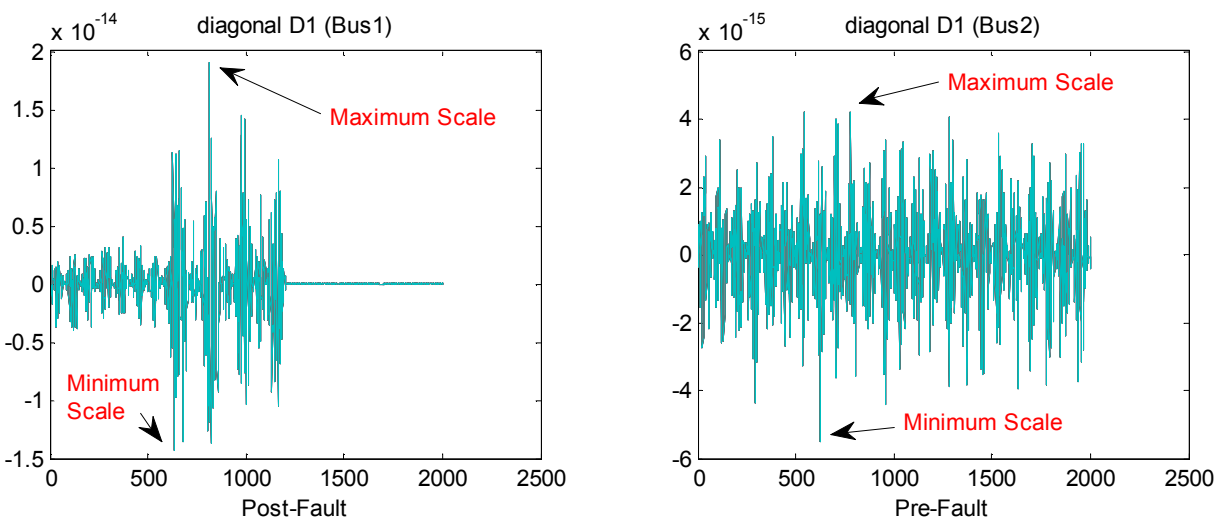

Figure 10. Diagonal Component of the Current Signal on the B2 (Pre-Fault) and on the B1 (Post-Fault).

Suppose a single phase fault occurred to ground (A-g) with a fault of $0.001 \mathrm{ohms}$ at a distance of $40 \mathrm{~km}$ from the transmission line. In this case, need to transform a wavelet signal from a prefault current (B2) and after a fault (on the B1). In Figures 7, 8, 9, 10 , the approximate component, the horizontal component, the vertical component, and the diagonal component of each signal for this fault is shown, respectively.

In the following, must extract the maximum and minimum scales of each component, the values of which is shown in Table 1.

Table 1. Maximum and Minimum Scale Components of Current Signal Components.

\begin{tabular}{|c|c|c|c|c|c|}
\hline \multirow{2}{*}{$\begin{array}{l}\text { Pre-Fault } \\
\text { Components of the current } \\
\text { signal (at Bus 2) }\end{array}$} & \multicolumn{5}{|c|}{ Post-Fault (A-g fault at 40 km) } \\
\hline & Maximum Scale & Minimum Scale & $\begin{array}{l}\text { Components of the current } \\
\text { signal (at Bus 1) }\end{array}$ & Maximum Scale & Minimum Scale \\
\hline Approximate (A1) & 56.54 & -56.57 & Approximate (A1) & 96.66 & -253.33 \\
\hline Horizontal (H1) & 0.168 & -0.2639 & Horizontal (H1) & 0.3355 & -0.309 \\
\hline Vertical (V1) & $1.0 \mathrm{e}-014 \times 0.6479$ & $1.0 \mathrm{e}-014 \times-0.5570$ & Vertical (V1) & $1.0 \mathrm{e}-013 \times 0.2090$ & $1.0 \mathrm{e}-013 \times-0.1007$ \\
\hline Diagonal (D1) & $1.0 \mathrm{e}-014 \times 0.42$ & $1.0 \mathrm{e}-014 \times-0.5509$ & Diagonal (D1) & $1.0 \mathrm{e}-013 \times 0.1816$ & $1.0 \mathrm{e}-013 \times-0.1728$ \\
\hline
\end{tabular}

By lowering the maximum and minimum values in the fault-free mode from the obtained values after the fault, obtain the positive difference values, and then sum up the values, therefore, the fault location is finally estimated.

In Table 2, the values are marked with a positive difference with the green color.

Table 2. The distance estimation fault.

\begin{tabular}{|c|c|c|c|c|c|c|c|c|}
\hline \multicolumn{5}{|l|}{ Db4 Maximum } & \multicolumn{4}{|c|}{ Db4 Minimum } \\
\hline Components & A1 & H1 & V1 & D1 & A1 & H1 & V1 & D1 \\
\hline $\begin{array}{l}\text { Differences } \\
\text { (Post-Fault) - } \\
\text { (Pre-Fault) } \\
\text { Estimated Dist }\end{array}$ & $\begin{array}{l}40.12 \\
(\mathrm{~km})=\end{array}$ & $\begin{array}{l}0.1675 \\
\mathrm{~km}\end{array}$ & $1.0 \mathrm{e}-013 \times 0.1442$ & $1.0 \mathrm{e}-013 \times 0.1396$ & -196.75 & -0.0451 & $1.0 \mathrm{e}-014 \times-0.4498$ & $1.0 \mathrm{e}-013 \times-0.1177$ \\
\hline
\end{tabular}

Finally, the full current chart of the proposed locator algorithm can be shown in Figure 11. 


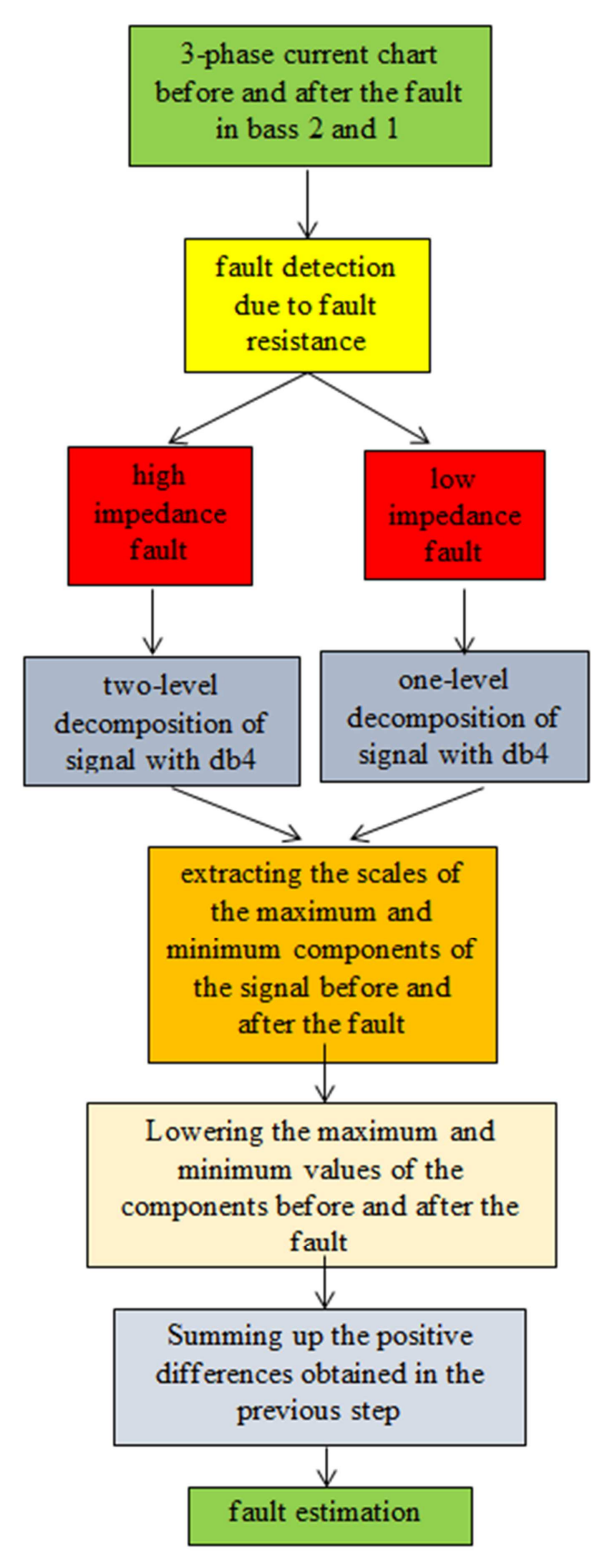

Figure 11.Current Chart of the Proposed Locator Algorithm.

\section{Simulation Results}

In this paper, the proposed algorithm is implemented on a $735 \mathrm{kV}$ transmission network with a frequency of $60 \mathrm{HZ}$, a 0 degrees-phase of source angle, an end-of-line load of 30,000 MVA with a phase angle of -28992 degrees with a length of $100 \mathrm{~km}$.

Table 3 indicates the results of testing the proposed algorithm for various faults at different intervals of the transmission line. As can be seen, for phase-to-phase faults, there is no fault resistance, only the level of a decomposition is used for faults in the ground, the fault resistance is used up to $75 \mathrm{ohms}$ of the level of a decomposition, and for fault resistance of up to $150 \mathrm{ohms}$, the level of fault analysis is also used.

In addition, the estimated fault estimate can be calculated from relation 2, the results of which are shown in Table 3.

$$
\mathrm{RE}=\frac{\mid \text { ActualLocation-EstimatedLocation } \mid}{\text { Lengthof Line }} \times 100
$$

Table 3. Results of Testing the Proposed Algorithm.

\begin{tabular}{|c|c|c|c|c|c|}
\hline \multicolumn{3}{|c|}{ Actual values } & \multicolumn{2}{|c|}{ Estimated values } & \multirow{2}{*}{ RE(\%) } \\
\hline Fault type & $\mathbf{R}_{\mathrm{f}}(\mathrm{ohm})$ & $X(\mathrm{~km})$ & Xe (km) & Db4 Level & \\
\hline A-g & 0.001 & 40 & 40.29 & 1 & 0.29 \\
\hline A-B-g & 7 & 20 & 20.89 & 1 & 0.89 \\
\hline A-B-C & - & 50 & 50.65 & 1 & 0.65 \\
\hline C-g & 85 & 65 & 65.71 & 2 & 0.71 \\
\hline A-C-g & 100 & 80 & 78.82 & 2 & 1.18 \\
\hline B-C & - & 10 & 9.86 & 1 & 0.14 \\
\hline B-g & 75 & 40 & 40.13 & 2 & 0.13 \\
\hline B-C-g & 150 & 80 & 81.14 & 2 & 1.14 \\
\hline $\mathrm{A}-\mathrm{C}$ & - & 30 & 29.83 & 1 & 0.17 \\
\hline A-B & - & 90 & 89.59 & 1 & 0.41 \\
\hline A-g & 15 & 15 & 15.18 & 1 & 0.18 \\
\hline A-C-g & 95 & 25 & 25.23 & 2 & 0.23 \\
\hline A-B-C-g & 20 & 35 & 35.87 & 1 & 0.87 \\
\hline
\end{tabular}

\section{Conclusion}

In this paper, signal processing techniques are used to locate the fault. One of these commonly used functions is the wavelet transform that allows the extraction of high and low frequency components. Since high-frequency components are created at the time of the failure, in this case, the wavelet transform can play a significant role. The main idea of this article is the wavelet transform of the data recorded by the relay before the fault (pre-fault) at the end of the line and after the fault (post-fault) at the beginning of the line. Finally, we have been able to estimate the fault location by comparing the scales obtained from this transform.

Meanwhile, this algorithm is designed to estimate the fault distance by varying the signal decomposition level for low impedance faults to high impedance. The simulation results reveal that the maximum estimated fault in this scheme is $1.18 \%$.

\section{References}

[1] De Andrade, L., De Leão, and T. Ponce., "Impedance based fault location analysis for transmission lines", Transmission and Distribution Conference and Exposition (T\&D), 2012 IEEE PES.

[2] Dashtdar, Masoud, Rahman Dashti, and Hamid Reza Shaker. "Distribution network fault section identification and fault location using artificial neural network." 2018 5th International Conference on Electrical and Electronic Engineering (ICEEE). IEEE, 2018.

[3] Dashtdar, Masoud. "Fault Location in Distribution Network Based on Fault Current Analysis Using Artificial Neural Network." Journal of Electrical \& Computer Engineering 1.2 (2018): 18-32.

[4] Chiradeja, Pathomthat, and Atthapol Ngaopitakkul. "Classification of Lightning and Faults in Transmission Line Systems Using Discrete Wavelet Transform." Mathematical Problems in Engineering 2018 (2018). 
[5] Lopes FV, Kusel BF, Silva KM., "Traveling Wave-Based Fault Location on Half-Wavelength Transmission Lines", IEEE Latin America Transactions 14.1 (2016).

[6] Bo ZQ, Weller G, Redfern MA, "Accurate fault location technique for distribution system using fault-generated highfrequency transient voltage signals", Generation, Transmission and Distribution, IEE Proceedings-. Vol.146. No. 1. IET, 1999.

[7] Rao A, Bogale B, "Accurate Fault Location Technique on Power Transmission Lines with use of Phasor Measurements", International Journal of Engineering Research and Technology. Vol. 4. No. 02 (February-2015). ESRSA Publications, 2015.

[8] $\mathrm{Xu} \mathrm{Z}$, Zhang Z, "What accuracy can we expect from the single-ended fault locator?", Protective Relay Engineers,2015 68th Annual Conference for. IEEE, 2015.

[9] Venugopal M, Tiwari C, "A novel algorithm to determine fault location in a transmission line using PMU measurements", Smart Instrumentation, Measurement and Applications (ICSIMA), 2013 IEEE International Conference on. IEEE, 2013.

[10] Elkalashy NI, Kawady TA, Khater WM, Taalab AM," Unsynchronized Fault-Location Technique for Double-Circuit Transmission Systems Independent of Line Parameters", IEEE Transactions on Power Delivery.2015.

[11] Kapoor, Gaurav. "A Fault-location Evaluation Method of a $330 \mathrm{kV}$ Three-Phase Transmission Line by Using Discrete Wavelet Transform." International Journal of Engineering Design \& Analysis 1.1 (2018): 5-10.
[12] Magnago, F. H. and Abur, A., "Fault Location Using Wavelet", IEEE Trans. on Power Delivery, Vol. 13, No.4, PP. 1475-1480, October 1998.

[13] Chen, Yann Qi, Olga Fink, and Giovanni Sansavini. "Combined fault location and classification for power transmission lines fault diagnosis with integrated feature extraction." IEEE Transactions on Industrial Electronics 65.1 (2018): 561-569.

[14] Wang, Mei, Changfeng Xu, and Huimin Lu. "Fault Location Without Wave Velocity Influence Using Wavelet and Clark Transform." Artificial Intelligence and Robotics. Springer, Cham, 2018. 321-326.

[15] Abraham, Sherura. "IMPROVING FAULT LOCATION OF THE ARC REFLECTION METHOD USING THE CONTINUOUS WAVELET TRANSFORM." (2018).

[16] Sarkar, Animesh, and Bikash Patel. "RBF Neural NetworkBased Wavelet Packet Energy-Aided Fault Localization on a Hybrid Transmission Line." Advances in Communication, Devices and Networking. Springer, Singapore, 2018. 807-815.

[17] Saini, Makmur, et al. "Algorithm for Fault Location and Classification on Parallel Transmission Line using Wavelet based on Clarke's Transform." International Journal of Electrical and Computer Engineering (IJECE) 8.2 (2018): 699-710.

[18] Dashtdar, Majid, Masoud Dashtdar. "Fault Location in the Transmission Network Based on the Analysis of the Recorded Current by the Relay Using a Discrete Wavelet Transform." (2019). 